\title{
Protein crosslinking as a therapeutic strategy for SOD1-related ALS
}

Md Amin Hossaina,b,1, Richa Sarin a,c,1, Daniel P. Donnelly, Jeremy B. Conway ${ }^{a}$, Samantha Watson ${ }^{a}$, Jenifer N. Winters ${ }^{a}$, Novera Alam ${ }^{a, b}$, Durgalakshmi Sivasankar ${ }^{a}$, Aparna C. Ponmudiyan ${ }^{a}$, Tanvi Gawde ${ }^{a}$, Sunanda Kannapadia, Jared R. Auclaira,b, Lee Makowskia,d, Gregory A. Petskoe,f, Dagmar Ringef, David J. Greenblattg, Mary Jo Ondrechen ${ }^{a}$, Yunqiu Chen ${ }^{c}$, Roman Manetsch ${ }^{\mathrm{a}, \mathrm{h}}$, and Jeffrey N. Agara,b,h,2

aDepartment of Chemistry and Chemical Biology, Northeastern University, Boston, MA 02115; bBarnett Institute of Chemical and Biological Analysis, Boston, MA 02115; 'Biogen Inc, Cambridge, MA 02142; dDepartment of Bioengineering, Northeastern University, Boston, MA 02115; ${ }^{\mathrm{A}}$ Ann Romney Center for Neurologic Diseases at Brigham and Women's Hospital, Harvard Medical School, Boston, MA 02115; fDepartments of Chemistry and Biochemistry, and Rosenstiel Center for Basic Medical Research, Brandeis University, Waltham, MA 02454; 9School of Medicine, Tufts University, Boston, MA 02111; hDepartment of Pharmaceutical Sciences, Northeastern University, Boston, MA 02115.

${ }^{*}$ Corresponding Author: Jeffrey N. Agar.

Email: j.agar@northeastern.edu

Author Contributions: M.A.H., R.S., and J.N.A. designed research; M.A.H., R.S., D.P.D., B.C.M., J.P.S., J.B.C., S.W., J.N.W., N.A., D.S., A.C.P., T.G., and S.K. performed research; M.A.H., R.S., B.C.M., S.W., J.N.W., N.A., L.M., D.J.G., M.J.O., Y.C., and J.N.A.; M.A.H., R.S., and J.N.A. wrote paper.

Competing Interest Statement: The authors declare no competing interest.

Classification: Biological sciences (Pharmacology)

Keywords: SOD1, Amyotrophic Lateral Sclerosis (ALS), pharmacological chaperone, cross-linking, stabilization

${ }^{1}$ M.A.H. and R.S. contributed equally to this work.

2To whom correspondence may be addressed. Email: j.agar@northeastern.edu

\begin{abstract}
Mutations in the gene encoding Cu-Zn superoxide dismutase 1 (SOD1) cause a subset of familial amyotrophic lateral sclerosis (fALS). One effect of these mutations is that SOD1, which is normally a stable dimer, dissociates into toxic monomers. Considerable research efforts have been devoted to developing compounds that stabilize the dimer of fALS SOD1 variants, but these have not yet resulted in an approved drug. We demonstrate that a cyclic thiosulfinate cross-linker can stabilize prevalent disease-causing SOD1 variants. The degree of stabilization afforded by cyclic thiosulfinates (up to $24{ }^{\circ} \mathrm{C}$ ) is unprecedented. We show this compound works rapidly in vivo with a half-life of $\sim 3$ days. The efficacy, low toxicity, and
\end{abstract}


pharmacodynamics of cross-linker mediated stabilization make it a promising therapeutic approach for SOD1-related fALS.

Significance statement: Cyclic thiosulfinate S-XL6 enables the kinetic stabilization of ALS-associated SOD1 variants, in vivo.

\section{Introduction}

ALS is a fatal neurodegenerative disease that often leads to death within $2-5$ years of diagnosis $(1,2) .5 \%-$ $10 \%$ of ALS cases are familial while the rest are sporadic $(3,4)$. Over 180 SOD1 mutations in the gene encoding SOD1 contribute to approximately $20 \%$ of fALS cases $(5,6)$. These mutations are dominantly inherited, highly penetrant, and associated with varying degrees of disease severity and loss of enzymatic activity $(7,8)$. For example, patients harboring the SOD1 variant, SOD1A4V tend to survive one year after diagnosis, whereas those with SOD1 ${ }^{\mathrm{H} 46 \mathrm{R}}$ average 18 years after diagnosis (9). A number of studies have implicated wild-type SOD1 in sporadic ALS. For example, post-translational modification (PTMs) such as oxidation of Cys111 (10) are toxic and autoantibodies (11) to SOD1 are more prevalent. The role of wildtype SOD1 in ALS remains a subject of debate (12).

Wild-type SOD1 is a dimer. A common property of ALS-associated SOD1 mutations is that they increase the propensity for the dissociation of the SOD1 dimer (13). Small molecules are therefore being developed to stabilize the quaternary structure of fALS SOD1 variants $(14,15)$. An analogous strategy was employed successfully for tafamidis, a drug for transthyretin amyloidosis and transthyretin cardiomyopathy, which stabilizes the native transthyretin tetramer (16). However, this strategy has not yet resulted in a treatment for SOD1-related fALS. For example, molecules intended to stabilize SOD1 via non-covalent interactions at the dimer interface (17) instead bound to the $\beta$-barrel region of the SOD1 aggregates (14) and often exhibited plasma protein binding (15).

We are pursuing an alternative approach to stabilize the SOD1 dimer. We postulated that two free cysteines (a sulfhydryl, i.e., not involved in a disulfide) situated on adjacent monomers, Cys 111a and Cys111b (within 9-13 $\AA$ of each other, depending upon Cys residue orientation), could be cross-linked to prevent dimer dissociation. Cysteine residues can be targeted with high selectivity due to the unique reactivity 
(nucleophilicity and polarizability) of the thiolate functional group. This is evidenced by numerous drugs that form covalent bonds to cysteine residues, including the irreversible aldehyde dehydrogenase (ALDH1A1) inhibitor disulfiram (Antabuse) (18); the blockbuster proton pump inhibitors, e.g., omeprazole (Prilosec) and its single enantiomer esomeprazole (Nexium) (19); and second-generation kinase inhibitors, e.g., afatinib (Gilotrif) (20). In proof-of-concept experiments, we demonstrated that tethering the Cys111 pair on the disease variants SOD1G93A and SOD1G85R could stabilize the SOD1 dimer and rescue superoxide dismutase activity (21). The bifunctional maleimides used in these studies, however, are toxic (22) because they target any exposed free cysteine, many of which serve essential catalytic and redox roles for other proteins. The molecule ebselen, which stabilizes fALS SOD1 variants by binding Cys111 (23) could exhibit a similar liability, as evidenced by its off-target binding to Cys6 (24). Therefore, a therapeutically viable cross-linking mechanism requires the ability to bind the Cys 111 pair while avoiding other cysteines.

We recently introduced cyclic thiosulfinates, which selectively cross-link pairs of free cysteines, while avoiding "dead-end" modifications (i.e., not resulting in a cross-link) of lone cysteines (25). Cyclic thiosulfinates are one oxygen ( $S$-oxo) derivatives of cyclic disulfides. Well-known and well-tolerated cyclic disulfides include the natural product asparagusic acid and the multi-enzyme cofactor and dietary supplement $\alpha$-lipoic acid. The cyclic thiosulfinate 1,2-dithiane-1-oxide (sulfur cross-linking 6-membered ring, hereafter S-XL6, Fig. 1) and $\beta$-lipoic acid (the $S$-oxo derivative of $\alpha$-lipoic acid), (25) target the Cys111a and Cys111b residues on adjacent SOD1 monomers, forming a disulfide bond with each cysteine thiolate. To test the efficacy of S-XL6, we have chosen disease variants ranging from metallated, fully active $\left(\mathrm{SOD} 1^{\mathrm{A} 4 \mathrm{~V}}\right.$ and SOD1 $\left.{ }^{\mathrm{G} 93 \mathrm{~A}}\right)$ to mostly inactive with impaired metal binding (SOD1 ${ }^{\mathrm{H} 46 \mathrm{R}}$ and SOD1 $\left.{ }^{\mathrm{G} 85 \mathrm{R}}\right)$. These same variants also span a wide range of prognoses (1 year to 18 years survival). In this study, we demonstrate S-XL6-mediated dimer stabilization of these fALS SOD1 variants; assess the impact of the cross-linker on the thermal stability and structure; test in cellulo activity and toxicity, and demonstrate target engagement in an ALS mouse model. 


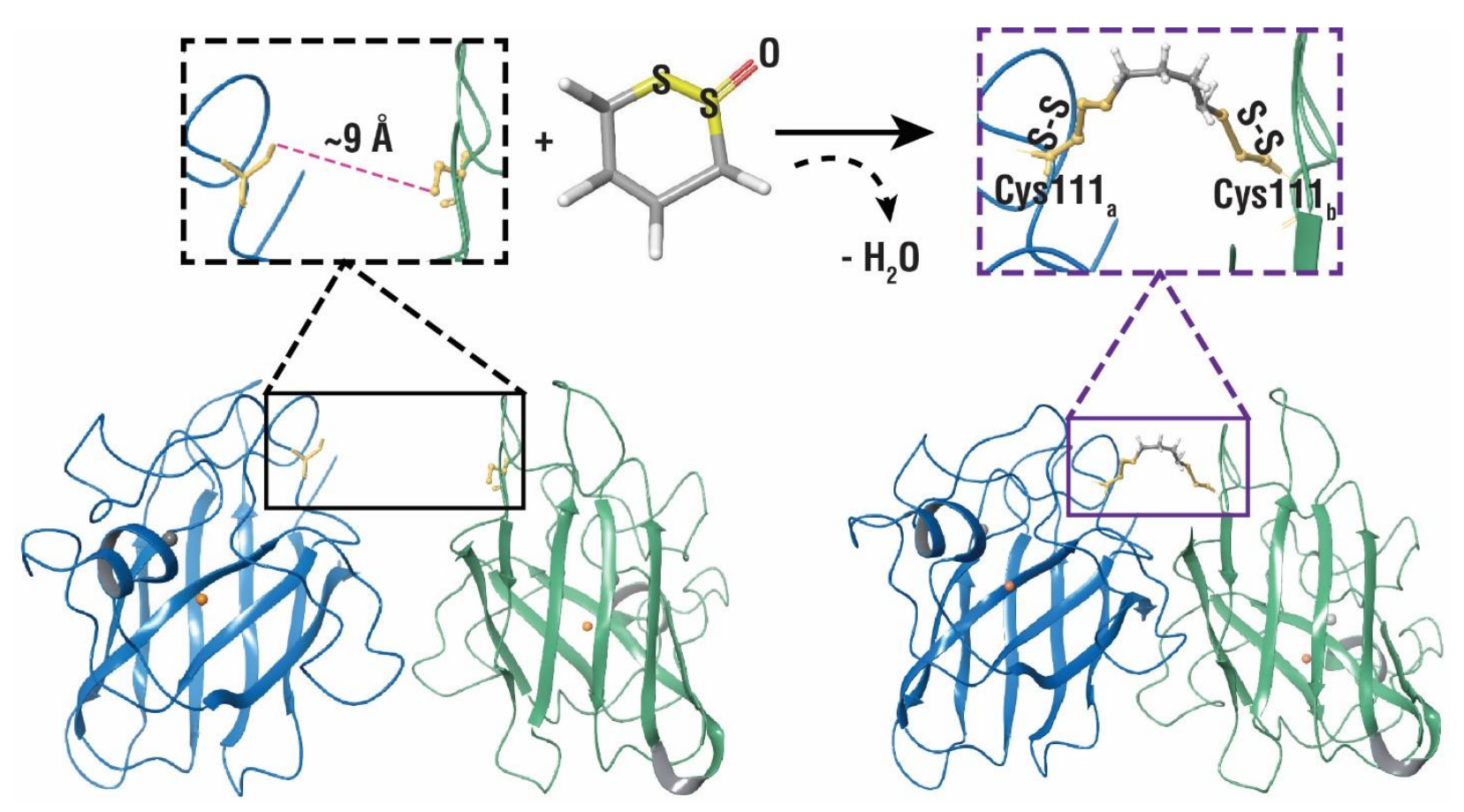

Fig. 1. Cyclic thiosulfinate S-XL6 cross-links SOD1 variants via Cys111 residues on adjacent monomers. Crystal structure of wild-type SOD1 (PDB ID: 1SPD, cartoon representation generated with Maestro 11.8) highlighting opposing Cys111 residues on both monomer A (blue) and monomer B (green) with a representation of the S-XL6 cross-linked SOD1 dimer. The cross-linking reaction proceeds through an initial thiolate-disulfide interchange between the cyclic thiosulfinate and a cysteine thiolate, generating a sulfenic acid intermediate due to the opening of the ring structure. This sulfenic acid intermediate forms a cross-link by rapid condensation with a second cysteine thiolate. $\mathrm{Cu}$ and $\mathrm{Zn}$ molecules are represented by orange and grey spheres, respectively. 


\section{Results}

\section{S-XL6 cross-links and stabilizes fALS SOD1 variants}

We employed a mass spectrometry (MS) assay for intact protein crosslinking (21). In this assay, any noncovalent (i.e., native) dimer is dissociated by a combination of acidic, organic media and MS source conditions. Using this assay, we observed S-XL6-dependent formation of cross-linked dimers for wild-type SOD1, SOD1 ${ }^{\mathrm{A} 4 \mathrm{~V}}$, SOD1 ${ }^{\mathrm{G} 93 \mathrm{~A}}$, SOD1 ${ }^{\mathrm{H} 46 \mathrm{R}}$, and SOD1 ${ }^{\mathrm{G} 85 \mathrm{R}}$ (Fig. 2). This reaction was efficient (full conversion of monomer to dimer) and stoichiometric (occurring at ratios as low as 1:1 cross-linker to dimer). Dead-end modifications of SOD1 were not observed in these assays. We confirmed the mechanism of action (MoA, e.g., loss of oxygen from the cross-linker concomitant with dimer formation, Fig. 1) and determined the site of cross-linking using endoproteinase digestion and MALDI (Matrix-Assisted Laser Desorption Ionization) peptide mass fingerprinting analysis of cross-linked samples (Fig. S1).

Mutations in SOD1 that cause ALS destabilize the native dimer to varying degrees. Loss of stability of fALS variants correlates with disease severity, specifically with rapid progression (26). To understand how crosslinking effects SOD1 stability, we quantified changes in unfolding temperature $\left(\Delta T_{\mathrm{u}}\right.$, hereafter thermal stability). Purified wild-type, SOD1A4V, SOD1 ${ }^{\mathrm{G} 93 \mathrm{~A}}$, SOD1 ${ }^{\mathrm{H} 46 \mathrm{R}}$, and SOD1G85R proteins were treated with $S$ XL6. Thermally-induced unfolding of SOD1 variants was measured using a previously published method, Differential Scanning Fluorimetry (DSF) (Fig. 2, right) (27). The increases in thermal stability attained with our compounds $\left(14-24^{\circ} \mathrm{C}\right)$ compare favorably with that of other preclinical candidates for stabilizing SOD1 (e.g., $11^{\circ} \mathrm{C}$ ebselen analogues) (28), and with the only approved drug with a kinetic stabilizing mechanism, tafamidis $\left(6^{\circ} \mathrm{C}\right)(29)$. 


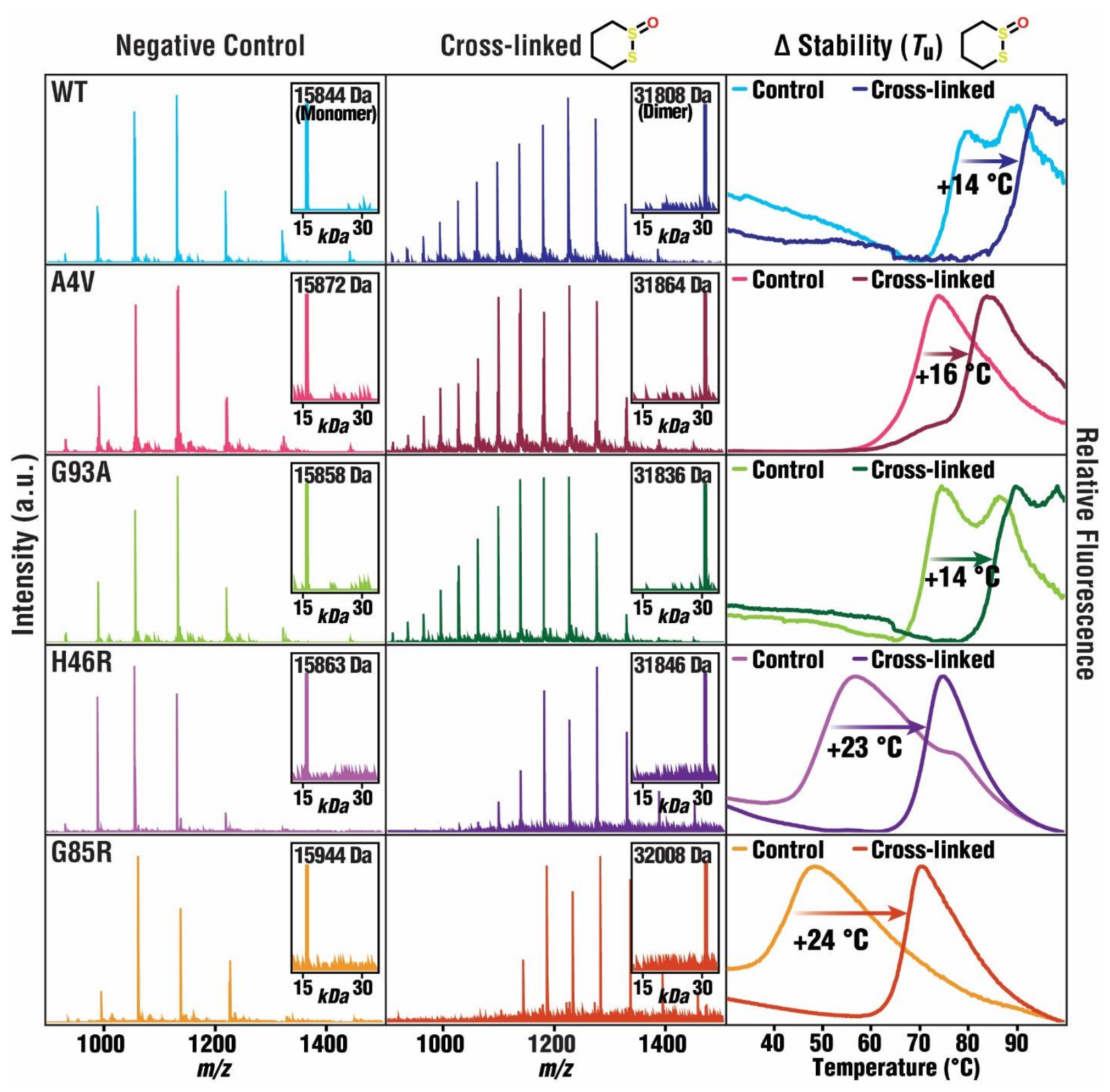

Fig. 2. S-XL6-mediated cross-linking and stabilization of wild-type and fALS SOD1 variants. MasS spectra of untreated (left column, average mass $\left[\begin{array}{l} \pm \\ \mathrm{Da}\end{array}\right]$ ) and $S-X L 6$ cross-linked (middle column, average mass $[ \pm 2 \mathrm{Da}]$ ) proteins are consistent with cross-linking. DSF results (right column) indicate that cross-linking increased the thermal stability of SOD1 and its variants. Note: two inflections can be observed when there is a mixture of partially (lower $\Delta T_{\mathrm{u}}$ ) and fully metallated (higher $\Delta T_{\mathrm{u}}$ ) SOD1 proteoforms, which applies to the following proteins: untreated wild-type SOD1 unfolds at $75.9^{\circ} \mathrm{C}$ and $87.6^{\circ} \mathrm{C}$; untreated SOD1 ${ }^{\mathrm{G} 93 \mathrm{~A}}$ unfolds at $70.6{ }^{\circ} \mathrm{C}$ and $84.4{ }^{\circ} \mathrm{C}$. We quantify $\Delta T_{\mathrm{u}}$ as the difference in unfolding temperature 
measured between the major inflections of the untreated and cross-linked samples. The unfolding temperature of the untreated and S-XL6 cross-linked SOD1 proteins are as follows: wild-type (WT) from $75.9^{\circ} \mathrm{C}$ to $90.2^{\circ} \mathrm{C}\left(\Delta T_{\mathrm{u}} \sim 14{ }^{\circ} \mathrm{C}\right)$; SOD $1{ }^{\mathrm{A} 4 \mathrm{~V}}$ from $62.9^{\circ} \mathrm{C}$ to $79.3^{\circ} \mathrm{C}\left(\Delta T_{\mathrm{u}} \sim 16^{\circ} \mathrm{C}\right)$; SOD $1{ }^{\mathrm{G} 93 \mathrm{~A} A}$ from $70.6^{\circ} \mathrm{C}$ to $85.0^{\circ} \mathrm{C}\left(\Delta T_{\mathrm{u}} \sim 14^{\circ} \mathrm{C}\right)$; SOD $1{ }^{\mathrm{H} 46 \mathrm{R}}$ from $46.3^{\circ} \mathrm{C}$ to $69.3^{\circ} \mathrm{C}\left(\Delta T_{\mathrm{u}} \sim 23^{\circ} \mathrm{C}\right)$; SOD $1^{\mathrm{G} 85 \mathrm{R}}$ from $40.8^{\circ} \mathrm{C}$ to $65.1^{\circ} \mathrm{C}$ $\left(\Delta T_{\mathrm{u}} \sim 24^{\circ} \mathrm{C}\right)$. All samples were analyzed in triplicate (standard errors $<0.3^{\circ} \mathrm{C}$ ).

\section{S-XL6 promotes SOD1 dimer formation in cellulo}

We characterized the effectiveness of our crosslinker using Hep G2 cells. SOD1 cross-linking was monitored using SDS-PAGE and western blotting. S-XL6 cross-linked wild-type SOD1 in cells in both PBS buffer and serum. The half maximal effective concentrations (EC $\left.\mathrm{E}_{50}\right)$ were circa (ca.) $5 \mu \mathrm{M}$ and $10 \mu \mathrm{M}$ (Fig. $\mathbf{3 A}$ ), respectively, consistent with minor association with serum proteins. The minimal plasma protein binding is promising, and is enabled by cyclic thiosulfinates' ability to avoid lone cysteines, including the highly abundant lone cysteine (Cys34) (30) of serum albumin. These results are also consistent with previous research indicating that cyclic thiosulfinates are actively transported across the cellular membrane (25) where they remain intact (31).

The cytotoxicity of S-XL6 was measured in Hep G2 using a standard MTT assay (LC50 446 $\mu \mathrm{M}$, Fig. 3B).

Given that the $\mathrm{LC}_{50}$ is $90 \mathrm{x}$ the $\mathrm{EC}_{50}, \mathrm{~S}-\mathrm{XL6}$ can promote dimer formation in cellulo with minimal toxicity. This warranted further exploration of S-XL6 as a potential preclinical candidate, vide infra. 

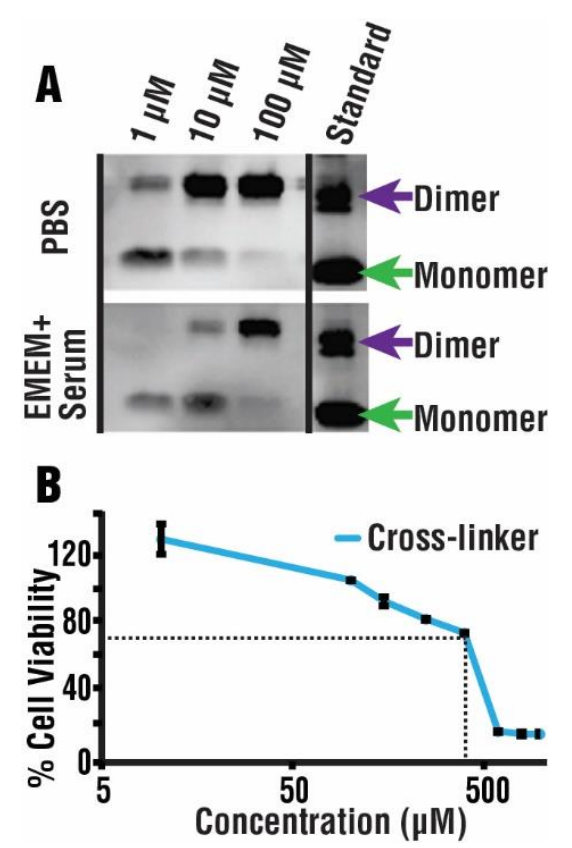

Fig. 3. Cross-linking at sub-toxic concentrations within cells. $(\boldsymbol{A})$ Western blot analysis using a SOD1selective antibody indicates that cross-linking proceeds in HEP G2 cells with an $\mathrm{EC}_{50}$ of $\sim 5 \mu \mathrm{M}$ (in PBS buffer) or $10 \mu \mathrm{M}$ (in complete growth media, including 10\% serum). (B) Low toxicity of S-XL6 (LC50 446 $\mu \mathrm{M})$ was observed using the MTT (3-(4,5-Dimethylthiazol 2-yl)-2,5-diphenyltetrazolium bromide) cytotoxicity assay (triplicate analysis). Results are shown as percentage of viable cells compared to a vehicle control. Note: cell viability $<70 \%$ (dotted line) is generally considered as the threshold for cytotoxicity, and viabilities $>100 \%$ indicate a trophic effect. Controls included EMEM with $0.1 \%$ DMSO (dimethyl sulfoxide, negative control) and $500 \mu \mathrm{M}$ of chlorpromazine (positive control).

\section{Target stabilization and pharmacodynamic profiling}

To assess the time course of S-XL6 target engagement in vivo, pharmacodynamic (PD) profiling was carried out using mice expressing human fALS variant, namely the well-established "fast-line" B6SJL$\operatorname{Tg}\left(\mathrm{SOD} 1{ }^{*} \mathrm{G} 93 \mathrm{~A}\right) 1 \mathrm{Gur} / \mathrm{J}$ (13). Mice were dosed with S-XL6 via intravenous (IV) injection and blood was collected at different time points, post dose, from the tail vein. To detect the intact SOD1 ${ }^{\text {G93A }}$ protein-crosslinker complex, we utilized a facile MS assay, namely a combination of solvent-extraction, hemoglobin precipitation, and liquid chromatography coupled with mass spectrometry (LC-MS) (32). We observed that 
a single IV dose of S-XL6 at $10 \mathrm{mg} / \mathrm{kg}$ converted $63 \%$ of the SOD1G93A (Fig. 4D) into a cross-linked dimer at 1-hour post-dose. A notable half-life of ca. 68 hrs. was observed (Fig. 4B). The accuracy of the MS assay (Fig. 4) allows us to confirm the following aspects of our proposed MoA (Fig. 1), in vivo: cyclic thiosulfinate's oxygen is lost upon cross-linking, and only one cross-linker binds per SOD1 dimer.

Previous studies have shown that Small Angle X-Ray Scattering (SAXS) can monitor changes to protein tertiary and quaternary structure in solution. Therefore, SAXS (Fig. $4 E$ and $F$ ) was performed to determine the effects of cross-linking upon the structure of fALS variant SOD1 ${ }^{\mathrm{G} 93 \mathrm{~A}}$, the same variant expressed by the mice that were dosed in the present study. For SAXS studies, SOD1G93A was purified from yeast because the milligram protein quantities required could not be obtained from mice. Whereas previous SAXS studies of SOD1G93A preparations showed a radius of gyration $(R g)$ of 20 to $24 \AA(33,34)$, our SAXS data for asisolated SOD1G93A were consistent with a relatively unfolded (possibly aggregating) SOD1 structure and could not be fit to determine an $R g$. The $R g$ of $20 \AA$ estimated from scattering data was consistent with $S$ XL6 treated SOD1 ${ }^{\mathrm{G} 93 \mathrm{~A}}$ being a native dimer. 
A

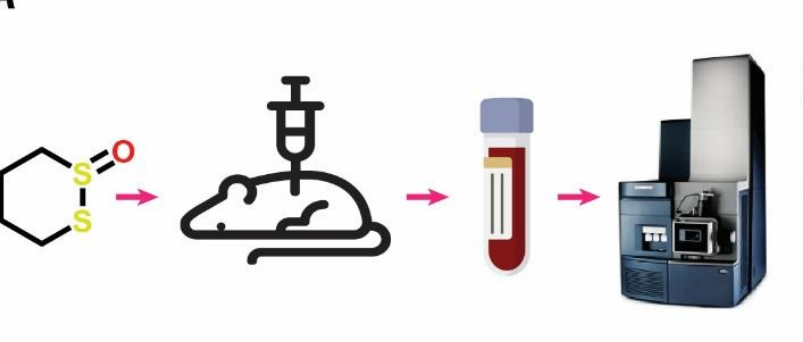

B
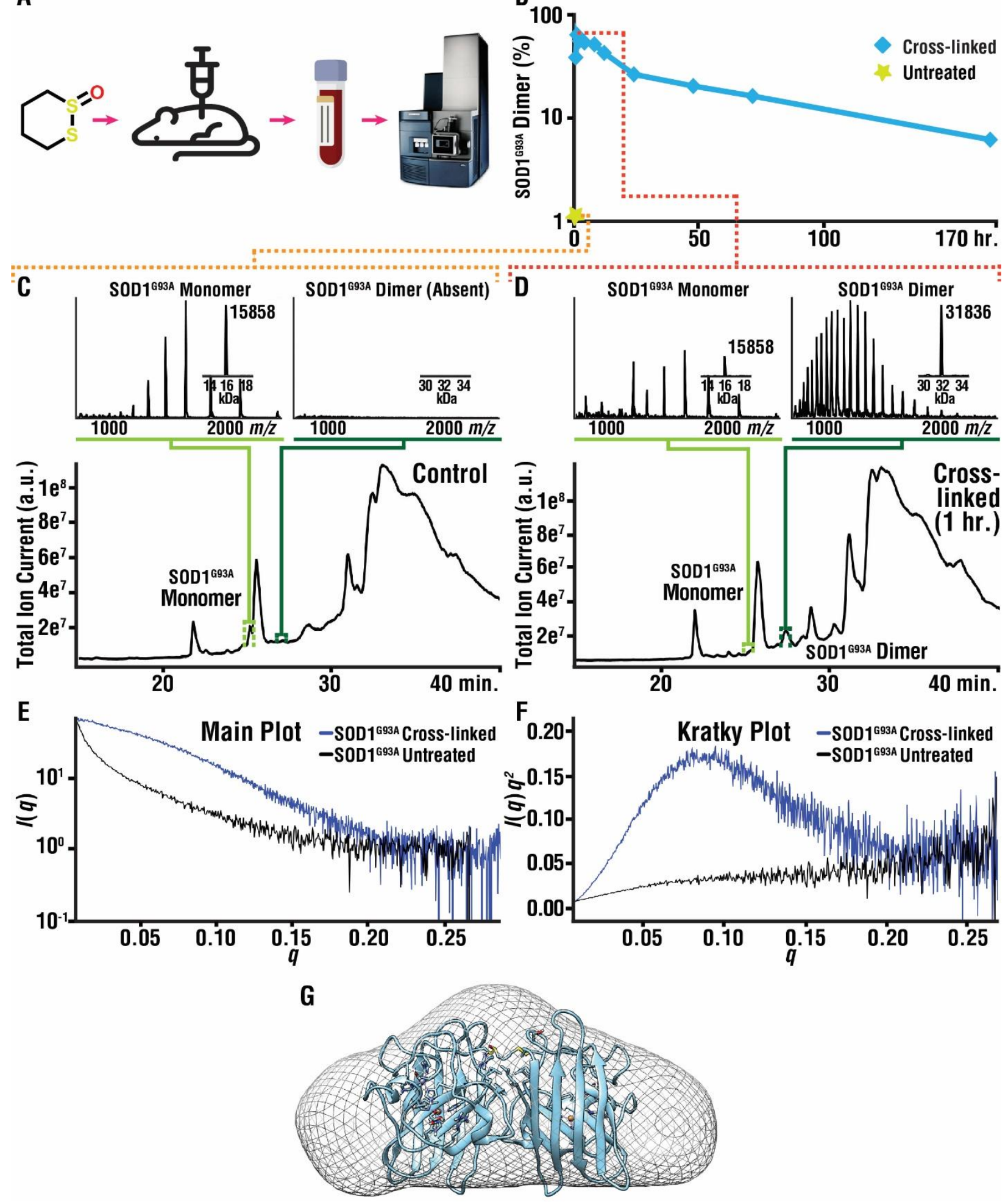

Fig. 4. S-XL6 cross-links SOD1 in an ALS mouse model \& results in a more folded SOD1 dimer. $(A)$ Schematic of the pharmacodynamic workflow. (B) Pharmacodynamic profiling of red blood cell (RBC) 
proteins by LC-MS analysis indicates the formation of an S-XL6 cross-linked dimer in treated SOD1G93A mice. Hemizygous fALS SOD1G93A mice were dosed once at $10 \mathrm{mg} / \mathrm{kg}$ with $S$-XL6 via tail vein injection, blood was collected periodically over a 7-day period, and LC-MS analysis ( $\boldsymbol{C}$ and $\boldsymbol{D}$ ) was performed to assess percentage of cross-linked SOD1 (details in Table S1). Spectra represent a 6 second average at peak apex. The half-life of cross-linked SOD1 ${ }^{\mathrm{G} 93 \mathrm{~A}}$ dimer was determined to be ca. 68-hours. ( $\boldsymbol{E}$ and $\boldsymbol{F}$ ) In vitro SAXS experiments for SOD1G93A: Semi-log plot of the scattering intensity (I, log scale) as a function of

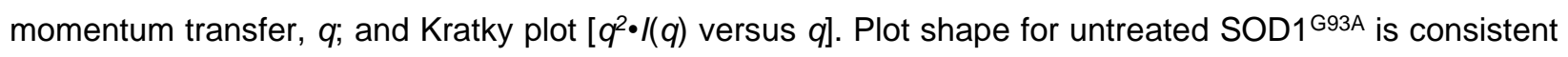
with an unfolded protein, whereas plot shape for cross-linked SOD1G93A is consistent with a folded, globular structure. The estimated radius of gyration is $\sim 20 \AA$. (G) A 3-D reconstruction of cross-linked SOD1G93A is superimposed upon the SOD1G93A crystal structure (PDB: 3GZO).

\section{Higher order structural analysis of cross-linked SOD1}

To determine the impact of cross-linking on the structure of fALS SOD1 variants, we utilized hydrogen deuterium exchange mass spectrometry (H/D-X MS). H/D-X MS assesses structure and dynamics by measuring differences in deuterium uptake (35). Following cross-linking, we observed that the structures of fALS SOD1 variants bear a closer resemblance, but do not fully recapitulate, the wild-type SOD1 structure (Fig. 5). For example, decreased uptake at the $\mathrm{N}$ - and C-termini of SOD1 (the dimer interface) was observed in all cross-linked variants. In all but one variant, SOD1G93A, the differences in uptake around residues 37-43 more closely resembled wild-type. Notably, structural changes in this region are responsible for the "gain of interaction" with the disordered electrostatic loop, which has been proposed to lead to the aggregation of fALS variants (36).

Previous studies have shown that fALS variants can be broadly classified as enzymatically active "wildtype-like variants" (e.g., SOD $1^{\mathrm{A} 4 \mathrm{~V}}$ and SOD $1^{\mathrm{G} 93 \mathrm{~A}}$ ), and as inactive, less-folded, predominantly monomeric (36, 37), "metal-deficient" variants (e.g., SOD1G85R and SOD1H46R) $(38,39)$. Consistent with this, larger differences in uptake via H/D-X MS were observed for SOD1 ${ }^{\mathrm{G} 85 \mathrm{R}}$ and SOD1 ${ }^{\mathrm{H} 46 \mathrm{R}}$. Subtle $(<5 \%)$ differences in deuteration levels were also observed in other regions of the SOD1 variants. In summary, cross-linking makes the structure and dynamics of fALS SOD1 variants more similar to that of wild-type SOD1, and in a manner that is consistent with reducing their aggregation propensity. 


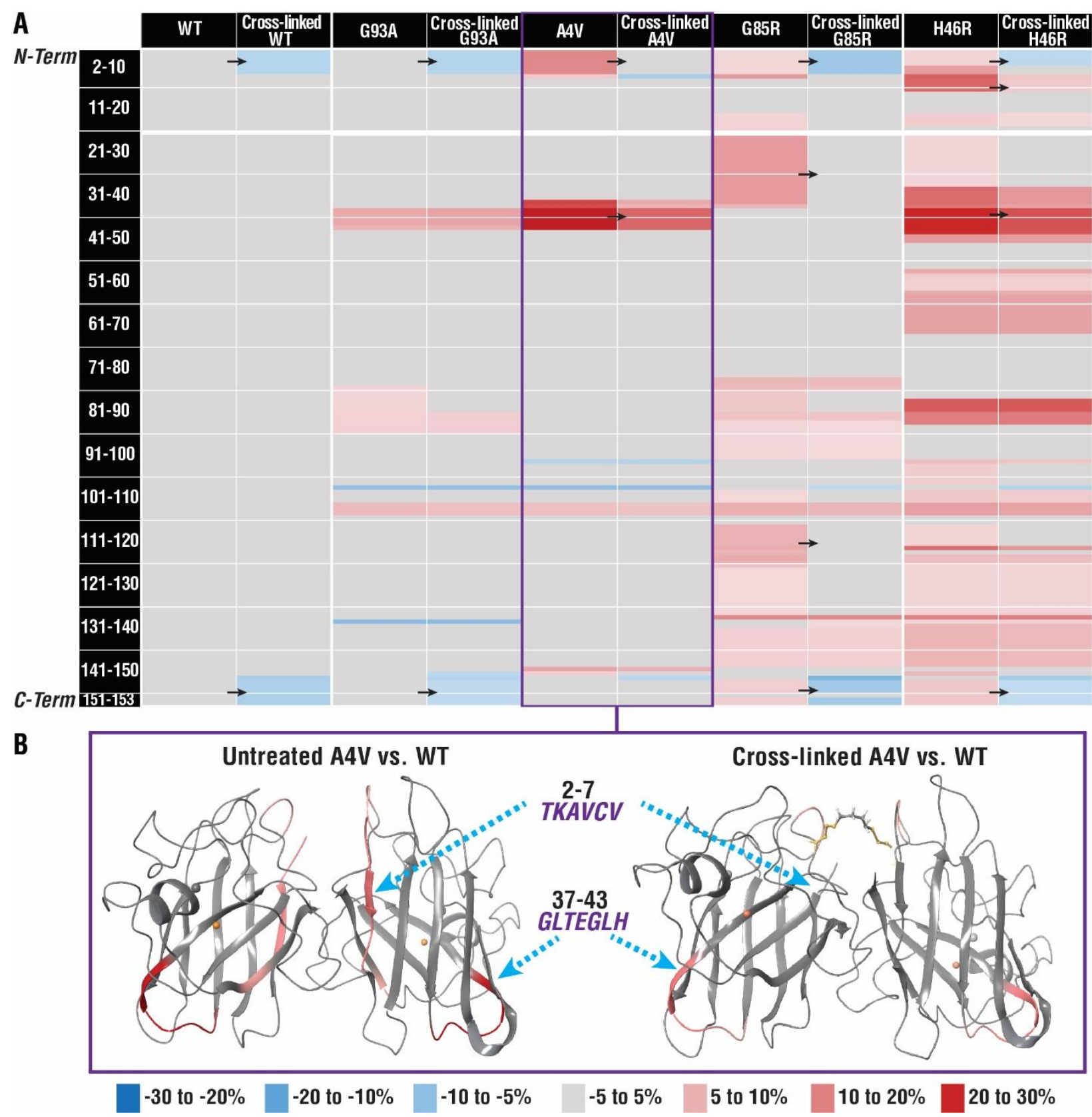

Fig. 5. Cross-linking enhances the structure of fALS SOD1 variants. Differences in deuterium uptake $(\Delta \mathrm{U}$, legend shown below part b) of untreated and cross-linked variants for the 4-hour timepoint compared to the wild-type SOD1 (WT) protein are reported here. $(\boldsymbol{A}) \rightarrow$ indicates areas where prominent shifts in $\Delta \mathrm{U}$ were observed (e.g., residues $2-7$ for SOD1A4V untreated $13.8 \%$ to $1.2 \%$ cross-linked, for full results see Fig. S2). (B) $\Delta U$ for untreated and cross-linked SOD1 ${ }^{\mathrm{A} 4 \mathrm{~V}}$ mapped onto the cartoon representation of wild- 
type SOD1 structure (PDB ID: 1SPD), generated with Maestro 11.8. $\Delta \mathrm{U}$ for all timepoints (15s, 50s, 500s, 1 hour, 4 hours) are reported in Fig. S2.

\section{Discussion}

We have shown that a cyclic thiosulfinate cross-linker, S-XL6, cross-links and stabilizes SOD1 fALS variants with diverse physiochemical properties and disease severities. These variants included the prevalent G85R and H46R SOD1 variants, which provided a major challenge for our dimer cross-linking approach because they exist in a predominantly monomeric state. Notably, the $\sim 68$ hour biological half-life of the S-XL6 cross-linked complex is almost seven times higher than previously reported studies (e.g., 10 hour half-life of SOD1G93A) (40). DSF and SAXS results indicated that cross-linking increased stability and $\mathrm{H} / \mathrm{D}-\mathrm{X}$ results indicated that cross-linking should decrease the aggregation propensity of fALS variants. These results are promising given that structural instability and higher aggregation propensity are risk factors for SOD1-related fALS $(9,41)$, but are only the first step in therapy development. Additional preclinical studies e.g., addressing selectivity and Drug Metabolism and Pharmacokinetics (DMPK) are underway. The focus of this study was the kinetic stabilization of SOD1 dimer. The most effective preclinical therapeutic strategy for SOD1 related-fALS has been the stabilization of SOD1 via the CUATSM (Cu (II)diacetyl-bis(N(4)-methylthiosemicarbazone)-mediated incorporation of metals (42). We anticipate there would be a benefit to combining these approaches.

\section{Materials and Methods}

\section{Synthesis of cyclic thiosulfinate 1,2-dithiane-1-oxide (S-XL6)}

Synthesis of 1,2-dithiane-1-oxide (S-XL6) was achieved according to the previously published literature procedure (25). To a round-bottom flask was added $\mathrm{I}_{2}(2.08 \mathrm{~g}, 8.18 \mathrm{mmol}, 0.20$ equiv.) and DMSO (2.91 $\mathrm{mL}, 40.90 \mathrm{mmol}, 1.0$ equiv.). The resulting dark brown solution was stirred gently. 1,4-butanedithiol (4.76 $\mathrm{mL}, 40.90 \mathrm{mmol}, 1.0$ equiv.) was dissolved in $\mathrm{CH}_{2} \mathrm{Cl}_{2}(16.3 \mathrm{~mL})$ and added dropwise to the stirring solution of $\mathrm{I}_{2}$ in DMSO. The rate of stirring was increased gradually with the addition of 1,4-butanedithiol in $\mathrm{CH}_{2} \mathrm{Cl}_{2}$. Upon completion of addition the resulting solution was stirred for $1 \mathrm{~h}$ at $23^{\circ} \mathrm{C}$. The light brown solution was 
quenched with slow addition of $10 \%$ aq. $\mathrm{Na}_{2} \mathrm{~S}_{2} \mathrm{O}_{3}(25 \mathrm{~mL})$. The layers were separated, and the aqueous layer was extracted with $\mathrm{CH}_{2} \mathrm{Cl}_{2}(3 \times 50 \mathrm{~mL})$. The combined organic layers were concentrated under reduced pressure. The concentrated light-yellow oil was taken up in $100 \mathrm{~mL}$ EtOAc and washed with sat. aq. $\mathrm{NaCl}(50 \mathrm{~mL})$. The layers were separated, and the aqueous layer was extracted with EtOAc $(3 \times 75$ $\mathrm{mL}$ ). The combined organic layers were dried over $\mathrm{Na}_{2} \mathrm{SO}_{4}$ and concentrated under reduced pressure to give pure 1,2-dithiane (4.82 g, 98\% yield) as a faint yellow solid. $\mathrm{Rf}=0.80$ (5:1 hexanes:EtOAc). 1,2-dithiane was then used without further purification to form 1,2-dithiane-1-oxide (S-XL6).

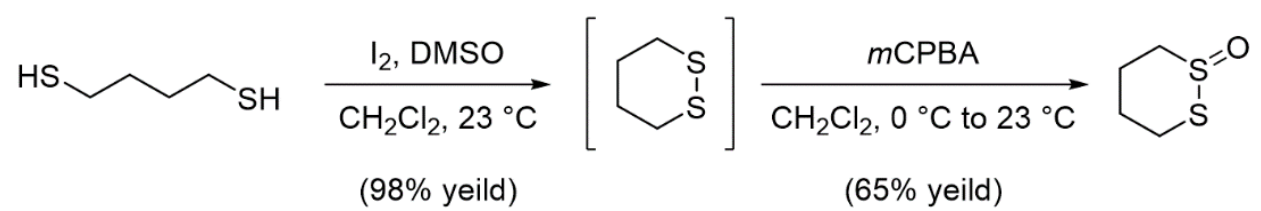

In a round-bottom flask, 1,2-dithiane $\left(4.82 \mathrm{~g}, 40.09 \mathrm{mmol}, 1.0\right.$ equiv.) was dissolved in $\mathrm{CH}_{2} \mathrm{Cl}_{2}(40.0 \mathrm{~mL})$ and cooled to $0{ }^{\circ} \mathrm{C}$. A solution of $m$ CPBA (9.48 g, 73\% weight, $40.09 \mathrm{mmol}, 1.0$ equiv) in $\mathrm{CH}_{2} \mathrm{Cl}_{2}(100.0$ $\mathrm{mL}$ ) was added dropwise via addition funnel. The resulting colorless, cloudy solution was allowed to stir at $0{ }^{\circ} \mathrm{C}$ for 1 hour while warming to $23^{\circ} \mathrm{C}$ and allowed to stir 1 hour at $23^{\circ} \mathrm{C}$. The reaction was cooled again to $0{ }^{\circ} \mathrm{C}$ and quenched with solid $\mathrm{Na}_{2} \mathrm{CO}_{3}(40.0 \mathrm{~g}, 377 \mathrm{mmol}, 1 \mathrm{~g}$ per mmol $\mathrm{mCPBA})$. The resulting dense slurry was filtered through a short plug of celite and concentrated under reduced pressure. The resulting cloudy oil was purified by flash column chromatography on silica gel with $2 \% \mathrm{MeOH} / \mathrm{CH}_{2} \mathrm{Cl}_{2}$ to give S-XL6 $(3.53 \mathrm{~g}, 64 \%$ yield $)$ as a colorless solid. $\mathrm{Rf}=0.33\left(2 \% \mathrm{MeOH} / \mathrm{CH}_{2} \mathrm{Cl}_{2}\right) .{ }^{1} \mathrm{H} \mathrm{NMR}(500 \mathrm{MHz}, \mathrm{CDCl} 3, \delta): 1.82-$ $1.91(\mathrm{~m}, 1 \mathrm{H}), 1.95-2.08(\mathrm{dtt}, \mathrm{J}=14.0,12.8,3.0 \mathrm{~Hz}, 1 \mathrm{H}), 2.09-2.17(\mathrm{~m}, 1 \mathrm{H}), 2.60-2.73(\mathrm{~m}, 2 \mathrm{H}), 3.03-3.13$ (dt, J = 13.2, 3.0 Hz, 1H), 3.17-3.24 (td, J = 13.4, 3.7 Hz, 1H), 3.61-3.71 (ddd, J = 14.0, 12.0, $2.5 \mathrm{~Hz}, 1 \mathrm{H}$ ) (Fig. S4.); ${ }^{13} \mathrm{C}$ NMR (100 MHz, $\mathrm{CDCl}_{3}, \delta$ ): 15.29, 23.47, 25.74, 51.92 (Fig. S5.). [M+H]+ was observed for $\mathrm{C}_{4} \mathrm{H}_{8} \mathrm{OS}_{2}$ and found 137.00914 Da (Fig. S6.) via Bruker 9.4T SolariX XR Mass Spectrometer (Bruker, Billerica, MA). Melting point found to be $83-86^{\circ} \mathrm{C}$ (lit $\left.83-86^{\circ} \mathrm{C}\right)$. 


\section{Expression and purification of wild-type SOD1, SOD1 ${ }^{\mathrm{A} 4 \mathrm{~V}}$, SOD1 ${ }^{\mathrm{G} 93 \mathrm{~A}}, \mathrm{SOD} 1^{\mathrm{H} 46 \mathrm{R}}$, and SOD1 ${ }^{\mathrm{G} 85 \mathrm{R}}$}

Expression and purification of SOD1 were conducted as previously published (21). Briefly, EGy118 SOD1 yeast were transformed with a wild-type SOD1, SOD1A4V , SOD1 ${ }^{\mathrm{G} 93 \mathrm{~A}}$, SOD1 ${ }^{\mathrm{H} 46 \mathrm{R}}$ or SOD1G85R YEp351 expression vector and grown at $30^{\circ} \mathrm{C}$ for 44 -hr. Cultures were centrifuged, lysed in a blender using $0.5 \mathrm{~mm}$ glass beads, and subjected to a $60 \%$ ammonium sulfate precipitation. Then the sample was centrifuged, and the resulting supernatant was diluted to $2.0 \mathrm{M}$ ammonium sulfate. The diluted sample was passed through a phenyl-sepharose 6 fast flow (high sub) hydrophobic interaction chromatography column (Cytiva Life Sciences, Marlborough, MA, USA) using a linearly decreasing salt gradient from high salt buffer (2.0 M ammonium sulfate, $50 \mathrm{mM}$ potassium phosphate dibasic, $150 \mathrm{mM}$ sodium chloride, $0.1 \mathrm{mM}$ EDTA, 0.25 mM DTT, pH 7.0) to low salt buffer ( $50 \mathrm{mM}$ potassium phosphate dibasic, $150 \mathrm{mM}$ sodium chloride, $0.1 \mathrm{mM}$ EDTA, $0.25 \mathrm{mM}$ DTT, pH 7.0) over $300 \mathrm{~mL}$. Fractions containing SOD1 eluted between 1.6 and $1.1 \mathrm{M}$ ammonium sulfate and were confirmed with SDS-PAGE. These fractions were pooled and exchanged into low salt buffer (10 mM Tris pH 8.0). Pooled fractions were then passed through a Mono Q 10/100 anion exchange column (Cytiva Life Sciences, Marlborough, MA, USA) using a linearly increasing salt gradient from low salt buffer to high salt buffer (10 mM Tris $\mathrm{pH} 8.0,1 \mathrm{M}$ sodium chloride) from $0-30 \%$. SOD1 fractions were collected between 5 and $12 \%$ high salt buffer and were confirmed with SDS-PAGE, western blot, and Fourier Transform Ion Cyclotron Resonance Mass Spectrometry (FT-ICR-MS).

\section{Confirmation of cross-link formation in vitro}

Wild-type SOD1, SOD1 ${ }^{\mathrm{A} 4 \mathrm{~V}}$, SOD1 ${ }^{\mathrm{G} 93 \mathrm{~A}}, \mathrm{SOD} 1^{\mathrm{H} 46 \mathrm{R}}$, and SOD1 ${ }^{\mathrm{G} 85 \mathrm{R}}$ stock solutions were diluted to $40 \mu \mathrm{M}$ in $10 \mathrm{mM}$ ammonium acetate, $\mathrm{pH}$ 7.4. DMSO stock of $S-X L 6$ was used to prepare $400 \mu \mathrm{M}(10 \mathrm{x})$ in $10 \mathrm{mM}$ ammonium acetate (0.5\% DMSO). Protein and cross-linker samples were combined in equal volumes (final concentration $20 \mu \mathrm{M}$ SOD1, $200 \mu \mathrm{M}$ cross-linkers, $0.25 \%$ DMSO) and incubated at $37^{\circ} \mathrm{C}$ for 4 hours at 350 rpm. Complete cross-linking was confirmed by mass spectrometry on a 9.4T Bruker SolariX (Bruker Corporation, Billerica, MA) via direct infusion as previously described $(25,43)$. Prior to infusion, samples were diluted to $1 \mu \mathrm{M}$ in 50:50 acetonitrile:water, with $0.1 \%$ formic acid. During analysis, 32 scans were 
acquired in positive mode and averaged. Funnel 1 and skimmer 1 were kept around $150 \mathrm{~V}$ and $20 \mathrm{~V}$, respectively, and funnel RF amplitude was held at $60.0 \mathrm{Vpp}$.

\section{Differential Scanning Fluorimetry}

The effect of cross-link formation on the thermal stability of SOD1 was determined by differential scanning fluorimetry as previously described $(21,27)$. Wild-type SOD1, SOD1A4V, SOD1 ${ }^{\mathrm{G} 93 \mathrm{~A}}$, SOD1H46R, and SOD1G85R $(20 \mu \mathrm{M}$ in $10 \mathrm{mM}$ ammonium acetate, $\mathrm{pH}$ 7.4) were incubated with ten-fold molar excess S-XL6 for 4 hours at $37{ }^{\circ} \mathrm{C}$ in protein low bind Eppendorf tubes using Eppendorf Thermomixer at $350 \mathrm{rpm}$ (Eppendorf North America, Enfield, CT, USA). After incubation, SYPRO Orange (Invitrogen Corporation, Carlsbad, California, USA), an environmentally sensitive fluorescent dye which is quenched in an aqueous environment but becomes unquenched once it binds hydrophobic residues, was added to the reaction mixture to a final concentration of 200X. The samples were then transferred to a fast optical 96-well reaction plate (Applied Biosystem, Life Technologies Corporation, Carlsbad, California, USA) and loaded on to the real-time PCR machine (Applied Biosystem, Life Technologies Corporation, Carlsbad, California, USA) after plate was spun down to eliminate bubbles. The Melt curve template in StepOne Plus software was used to set up a method. The SYBR reporter and ROX quencher data were collected for 35 cycles with a temperature gradient ranging from 25 to $99.9^{\circ} \mathrm{C}$ at a ramp rate of $0.5^{\circ} \mathrm{C} / \mathrm{min}$. The final concentration of DMSO in the reaction mixture was checked as it attributes to the denaturation of proteins. Dilutions were performed accordingly to maintain the final concentration of DMSO less than $1 \%$ (vol/vol). All samples were run in triplicate. The background data was subtracted from the average relative fluorescence and average derivate for each temperature point, and the data were normalized before Tus were quantified by averaging the negative first derivative of relative fluorescence of all three runs and identifying the local minima.

\section{Hep G2 cell culture}

The Hep G2 human hepatocarcinoma cell line (American Type Culture Collection, ATCC, Manassas, VA) was cultured using EMEM (Eagle's minimal essential medium, ATCC) supplemented with $10 \%$ FBS (fetal bovine serum, ATCC) and $1 \%$ penicillin streptomycin as previously described (31) $(10,000 \mathrm{units} / \mathrm{mL}$ 
penicillin and 10,000 $\mu \mathrm{g} / \mathrm{mL}$ streptomycin, Fisher scientific, Hampton, $\mathrm{NH})$. The cells were grown and subcultured around 72 hours at $37^{\circ} \mathrm{C}, 5 \% \mathrm{CO}_{2}$ under controlled humidity. The cells growth and morphology were inspected using an inverted Carl Zeiss microscope (Carl Zeiss Microscopy LLC, White Plains, NY).

\section{Cell viability assay/cell cytotoxicity assay}

Using manufacturer's instructions, Hep G2 cells were cultured for 24 hours with a density of $2 \times 10^{5} \mathrm{cells} / \mathrm{mL}$ in a 96-well culture plate at $37{ }^{\circ} \mathrm{C}, 5 \% \mathrm{CO}_{2}$ under controlled humidity. The cells were treated with S-XL6 ranging with $10,100,150,250,400,600,800$, and $1000 \mu \mathrm{M}$ for 24 hours (0.1\% DMSO). Cell cytotoxicity was performed via the MTT (3-(4,5-dimethylthiazol-2-yl)-2,5-diphenyltetrazolium bromide) assay at $570 \mathrm{~nm}$ absorbance using BioTek synergy H1 (Vermont, USA) plate reader according to previously published paper (31). The MTT stock was made at $5 \mathrm{mg} / \mathrm{mL}$ using $0.9 \%$ sodium chloride solution which was purchased from Sigma Aldrich (St. Louis, MO). Twenty-four hours after dosing the plate, the cultured medium was aspirated and replaced with the equal volume of MTT solution (10X dilution using EMEM complete media). The plate was incubated for 4 hours $\left(37^{\circ} \mathrm{C}, 5 \% \mathrm{CO}_{2}\right)$. The MTT solution was replaced by the equal amount of acidified isopropanol $(0.3 \%$ hydrochloric acid $(\mathrm{v} / \mathrm{v}))$ and then formed formazan was dissolved by shaking the plate gently for 30 minutes. The absorbance was measured at $570 \mathrm{~nm}$ for both the samples and acidified isopropanol for background calculation. Chlorpromazine and cells with $0.1 \%$ DMSO were used as positive control and vehicle, respectively. The cell viability of each concentrations was measured by normalizing against mean value of cells with $0.1 \%$ DMSO (vehicle).

\section{SDS-Page and western blot}

The Hep G2 human hepatocarcinoma cell line (American Type Culture Collection, ATCC, Manassas, VA) was cultured using both PBS buffer only and complete EMEM (Eagle's minimal essential medium, ATCC) media including 10\% FBS (fetal bovine serum, ATCC) and 1\% penicillin streptomycin (10,000 units $/ \mathrm{mL}$ penicillin and 10,000 $\mathrm{\mu g} / \mathrm{mL}$ streptomycin, Fisher scientific, Hampton, $\mathrm{NH}$ ). Cells were counted and checked for morphology using an inverted Carl Zeiss microscope (Carl Zeiss Microscopy LLC, White Plains, NY). A 
96-well plate (Corning Life Sciences, Tewksbury, MA) was used for culturing cells at $0.2 \mathrm{mill} / \mathrm{mL}$ concentration for 24 -hours at $37^{\circ} \mathrm{C}, 5 \% \mathrm{CO}_{2}$ under controlled humidity for western blot experiment. Cells (both PBS buffer only and completed EMEM media) were dosed with S-XL6 in triplicate at different concentrations ( $1 \mu \mathrm{M}, 10 \mu \mathrm{M}$, and $100 \mu \mathrm{M})$ and incubated for 30-minutes. In house purified wild-type SOD1 was used as positive control (standard) in the experiment. Existing buffer was aspirated and replaced with $30 \mu \mathrm{L}$ of lysis buffer $(150 \mathrm{mM} \mathrm{NaCl}, 1 \%$ Triton $\mathrm{X}-100,0.5 \%$ sodium deoxycholate, $0.1 \%$ SDS, and $50 \mathrm{mM}$ Tris, pH 8.0, all chemicals were purchased from Sigma Aldrich (St. Louis, MO)) and incubated for 10minutes followed by addition of non-reducing sample buffer. Samples were loaded into a Bio-Rad mini TGX gel (Bio-Rad Life Sciences, Hercules, CA) along with PageRuler ${ }^{\mathrm{TM}}$ prestained protein ladder (ThermoFisher Scientific, Waltham, MA) and ran using a Bio-Rad electrophoresis cell. Carefully the gel was removed and transferred into a beaker filled with transfer buffer (25mM Tris, 192mM glycine, 0.1\% SDS, and 10mM $\beta$ mercaptoethanol, all chemicals were purchased from Sigma Aldrich (St. Louis, MO)) and incubated briefly at $90^{\circ} \mathrm{C}$ and then transferred to a Trans-Blot Turbo mini nitrocellulose membrane using Trans-Blot Turbo Transfer system (Bio-Rad, Hercules, CA). The membrane was incubated overnight in antibody buffer (50mM tris- $\mathrm{HCl}, 150 \mathrm{mM}$ sodium chloride, $0.1 \%$ tween-20, $2.5 \%$ dry milk, all chemicals were purchased from Sigma Aldrich (St. Louis, MO)) with Cu/Zn SOD polyclonal antibody (1:1000 dilution, Enzo Life Sciences, Farmingdale, NY). Next day, the membrane was incubated with HRP-linked antibody buffer (1:1000 dilution, Cell Signaling Technology, Danvers, MA). The membrane was incubated briefly in dark with enhanced chemiluminescent (ECL, Thermo Fisher Scientific, Waltham, MA), followed by imaging using BioRad Chemidoc MP Imaging System (Bio-Rad, Hercules, CA).

\section{Mouse dosing and SOD1 isolation}

Pharmacodynamic profiling was carried out using hemizygous mice expressing human SOD1G93A ("fastline" Jackson Laboratory; B6SJL-Tg(SOD1*G93A)1Gur/J, also known as SOD1-G93A stock- 002726) (13). Mice were bred to express YFP in neurons in anticipation of BBB-penetration assays and Matrix-Assisted Laser Desorption lonization Mass Spectrometry Imaging (MALDI MSI) analysis. Extraction of SOD1G93A from red blood cell (RBC) protein was performed as previously described (32). S-XL6 was prepared in 1X 
PBS and mice were dosed at $10 \mathrm{mg} / \mathrm{kg}$ via intravenous (IV) injection in their lateral tail vein slowly and gently. Mice were trapped in restrainer and around $40 \mu \mathrm{L}$ of blood was collected in Greiner Bio-one $\mathrm{K}_{3}$ EDTA tubes (Greiner Bio-one, North Carolina, USA) post injection at 30-min, 1 hour, 2 hour, 4 hour, 8 hour, 12 hour, 24 hour, 48 hour, 72 hour, and 168 hour. Tubes were centrifuged at $2000 \mathrm{rpm}$ at $4{ }^{\circ} \mathrm{C}$ for 5 minutes immediately after collecting blood. Carefully plasma was discarded and acid citrate dextrose solution ( $0.48 \%$ citric acid, $1.32 \%$ sodium citrate, $1.47 \%$ glucose, all chemicals were purchased from Sigma Aldrich (St. Louis, MO)) was used to wash the sample by centrifuging at $2000 \mathrm{rpm}$ at $4{ }^{\circ} \mathrm{C}$ for 5 minutes. Following wash, the supernatant was removed, and RBC were lysed by the addition of $8 x$ equivalent of $10 \mathrm{mM}$ ammonium acetate. To the hemolysate, 0.15 equivalents of cold chloroform and 0.25 equivalents of cold ethanol was added. Samples were vortexed at $1800 \mathrm{rpm}$ at $4{ }^{\circ} \mathrm{C}$ for 15 minutes and centrifuged at 12000 rpm for 10 minutes. The supernatant was collected and stored at $-80{ }^{\circ} \mathrm{C}$ after flash freezing for LC-MS analysis. Prior to LC-MS analysis, samples were acidified to $10 \%$ formic acid. This study was performed in accordance with the Guide for the Care and Use of Laboratory Animals (National Institutes of Health, Bethesda, MD, USA). The protocol for this experiment with mice was approved by the Northeastern University Institutional Animal Care and Use Committee (IACUC).

\section{Confirmation of S-XL6 cross-linked SOD1 ${ }^{\mathrm{G} 93 \mathrm{~A}}$ dimer formation in vivo}

In vivo crosslinking from purified RBC was confirmed using an H-Class Acquity UPLC (Ultra Performance Liquid Chromatography) system coupled to a Xevo G2-S Q-ToF (Quadrupole Time of Flight) mass spectrometer (Waters Corp, Milford, MA) as previously described $(44,45)$. The LC system was equipped with reversed phase Acquity UPLC Protein BEH C4 (300 Å pore size, $1.7 \mu \mathrm{m}$ particle size, $100 \mathrm{~mm}$ bed length, $2.1 \mathrm{~mm}$ ID $\times 100 \mathrm{~mm}$ ) column at $60 \stackrel{\circ}{\mathrm{C}}$ with a flow rate of $0.2 \mathrm{~mL} / \mathrm{min}$. The mobile phase consisted of a mixture of $0.1 \%$ formic acid in water (solvent $\mathrm{A}$ ) and $0.1 \%$ formic acid in acetonitrile (solvent $\mathrm{B}$ ). The sample was introduced in $10 \%$ formic acid and $5 \mu \mathrm{L}$ was injected for analysis. UNIFI software (Waters Corp, Milford, MA) was used for system control and data processing. Solvents A and B were combined in a gradient: 0-2 min: 95\% A; 2-70 min: 30\% A; 72-75 min: 5\% A; 78-80 min: return to initial conditions. The MS was operated in positive mode and calibrated prior to analysis (ca. daily). The chromatographic window 
containing the SOD1G93A monomer and dimer were assigned using EICs (Extracted lon Chromatogram) $\mathrm{m} / \mathrm{z}$ 1322.5-1323.5 (monomer) and $\mathrm{m} / \mathrm{z}$ 1180.0-1180.5 (dimer) and mass spectra from this region were summed. Raw MS data from this composite spectrum were deconvoluted and average masses were calculated using the MaxEnt1 algorithm. The ratio of dimer intensity (31836 Da, SD 1.3 Da) to the sum of monomer (15858 Da, SD 0.8 Da) plus dimer intensity were then used to calculate the percentage of SOD1 ${ }^{\text {G93A }}$ dimer at different time points. 10 picomole of the SOD1G93A monomer and dimer were analyzed (as above) in individual experiments and their MS signal intensities were within 10\% (i.e., the differences in their chromatographic retention and ionization efficiency were within experimental error). The half-life of the S-XL6 cross-linked complex was calculated from apparent half-life of disappearance of the \% dimer by linear regression of the terminal beta phase (24 to 168 hours time point).

\section{Small-angle x-ray solution scattering (SAXS)}

SAXS data were collected at the G1 beamline at Cornell High Energy Synchrotron Source (CHESS). For each sample, two measurements were taken, one of the protein with buffer and one with buffer by itself. Solution scattering data were captured every second for 10 frames. The 10 frames of both buffer and protein were then averaged and the buffer was subtracted out to get the scattering for the protein. Samples were run in a 96-well plate and held at $4{ }^{\circ} \mathrm{C}$ continuously. Data collection was in the scattering angle $(q)$ range of 0.008 to $0.71 \AA^{-1}$ and processed using the software, RAW.

\section{Preparation of SOD1 samples for SAXS analysis}

SOD1 ${ }^{\mathrm{G} 93 \mathrm{~A}}$ was prepared at $3 \mathrm{mg} / \mathrm{mL}$ (approx. $190 \mu \mathrm{M}$ ) in HEPES buffer (115 mM NaCl, $1.2 \mathrm{mM} \mathrm{CaCl}$, 1.2 $\mathrm{mM} \mathrm{MgCl}_{2}, 2.4 \mathrm{mM} \mathrm{K}_{2} \mathrm{HPO}_{4}, 20 \mathrm{mM} \mathrm{HEPES}, \mathrm{pH}$ 7.4). Stock solutions of $S$-XL6 was freshly made at $10 \mathrm{mM}$ in HPLC grade methanol and diluted to $946 \mu \mathrm{M}$ in HPLC grade water (five-fold concentration of protein). $100 \mu \mathrm{L}$ of $3 \mathrm{mg} / \mathrm{mL}$ protein was mixed with $110 \mu \mathrm{L}$ of $946 \mu \mathrm{M}$ of $S$-XL6. Control sample contained $5 \% \mathrm{MeOH}$ (final conc. $2.5 \%$ ). Samples were then incubated at $37^{\circ} \mathrm{C}$ for 6 hours to ensure complete cross-linking. After incubation, excess compound was buffer exchanged out of each sample using a $10 \mathrm{kDa}$ MWCO ultrafiltration device. $320 \mu \mathrm{L}$ is diluted to $15 \mathrm{~mL}$ into HEPES buffer, spun down to approximately $500 \mu \mathrm{L}$, 
and resuspended in another $15 \mathrm{~mL}$ of HEPES buffer. After the final spin, samples were removed and concentrated in a smaller ultrafiltration device and brought to approximately $70 \mu \mathrm{L}$ final volume $(4.7 \mu \mathrm{M})$. Samples were flash frozen and stored at $-80^{\circ} \mathrm{C}$ prior to analysis.

\section{SAXS data analysis and reconstruction of molecular envelopes}

Programs within the ATSAS suite (46) were used to determine the estimated radius of gyration and threedimensional molecular envelopes for SOD1 ${ }^{\text {G93A }}$ with and without S-XL6 using the x-ray solution scattering data. The GNOM program was used to evaluate the pair distribution plot using an indirect Fourier transform. SOD1 ${ }^{\text {G93A }}$ with $S$-XL6 had a $D_{\max }$ value of $\sim 79 \AA$ whereas untreated SOD1G93A had a much higher $D_{\max }$ of over $200 \AA$ due to protein unfolding. The GASBOR program was used to generate three-dimensional $a b$ initio models of connected beads to fit the GNOM data, with the number of beads set approximately to the total number of amino acids in the SOD1 constructs. In order to assess the uniqueness of these solutions, 10 bead models were generated without any symmetry applied, then compared and averaged. Figures were produced using CHIMERA (47) followed by superimposition of envelopes.

\section{Peptide-level hydrogen deuterium exchange mass spectrometry (H/D-X MS)}

To 5 ul of $40 \mu \mathrm{M}$ SOD1 sample (in $10 \mathrm{mM}$ Ammonium Acetate in $\mathrm{H}_{2} \mathrm{O}, \mathrm{pH} 7.4$ ) was added $20 \mu \mathrm{l}$ of $99 \% \mathrm{D}_{2} \mathrm{O}$ sample buffer (10mM ammonium acetate in $\mathrm{D}_{2} \mathrm{O}, \mathrm{pH}$ 7.3), diluting the concentration of the protein down to $8 \mu \mathrm{M}$. For the reference sample, HPLC grade water was added instead of $\mathrm{D}_{2} \mathrm{O}$ buffer. Samples with $\mathrm{D}_{2} \mathrm{O}$ buffer were incubated at $37^{\circ} \mathrm{C}$ for five exposure timepoints: 15 seconds, 50 seconds, 500 seconds, $1 \mathrm{hr}$, and 4 hrs. All exchange reactions occurred at $37^{\circ} \mathrm{C}, \mathrm{pH} \sim 7.4$ to mimic in vivo conditions. The reaction mixture was quenched by the addition of $25 \mu \mathrm{L}$ of quench buffer ( $8 \mathrm{M}$ Gunadinium Hydrochloride (GnHCL), $0.5 \mathrm{M}$ tris(2-carboxyethyl) phosphine (TCEP), 0.2M Citric Acid at $\mathrm{pH} 2.35$ ), lowering the $\mathrm{pH}$ of the final mixture down to $\mathrm{pH} 2.45$, diluting the concentration of protein in the sample down to $4 \mu \mathrm{M}$ while simultaneously denaturing the protein and reducing the disulfides. For the 15 second timepoint, to ensure timely quenching of the exchange reaction, $\mathrm{D}_{2} \mathrm{O}$ buffer previously stored at $3{ }^{\circ} \mathrm{C}$ was added and the incubation itself was performed at room temperature. All samples preparations were performed in 
triplicates, flash frozen immediately after the quenching reaction and stored at $-70 \stackrel{\circ}{\mathrm{C}}$ until analysis. Prior to analysis, $50 \mu$ l of $0.1 \%$ Formic $A c i d$ in $\mathrm{H}_{2} \mathrm{O}$ was added to the sample to reduce the $\mathrm{GnHCL}$ concentration down to $2 \mathrm{M}$, the recommended concentration threshold for the pepsin column. This was immediately followed by injecting the sample onto a Waters UPLC system designed for H/D-X MS analysis where the samples were digested, desalted, and separated, online. The digestion and trapping of peptides was carried out during a 3 minute trapping step over an immobilized pepsin column with a flow rate of $100 \mu \mathrm{l} / \mathrm{min}$ in $0.1 \%$ formic acid and water at $10^{\circ} \mathrm{C}$. The peptides were trapped on an ACQUITY HSS T3 $100 \AA$, $1.8 \mu \mathrm{M}$ trap column (Waters Corp, Milford, MA) maintained at $0 \stackrel{\circ}{\circ}$. At the end of the trapping step, within the $0{ }^{\circ} \mathrm{C}$ chamber, the flow was directed to the ACQUITY HSS T3 100Å, $1.8 \mu \mathrm{M}$ analytical column (Waters Corp, Milford, MA) at $75 \mu \mathrm{l} / \mathrm{min}$ (average back pressure was around $7500 \mathrm{psi}$ ). The analytical separation step was performed over a 9min gradient of 5-25\% (0-7min) of buffer B; 25-95\% (7-8.5min) of buffer B (buffer A, $0.1 \%$ formic acid in water, buffer $\mathrm{B}, 0.1 \%$ formic acid in acetonitrile). Eluate from the analytical column was directed into a Waters QToF Synapt G2 HD mass spectrometer with electrospray ionization and lock-mass correction (using the Glu-fibrinogen peptide). Blanks (data not shown) were used between each sample injection to ensure there is no carryover of peptides between runs. Mass spectra were acquired between $50-2000 \mathrm{~m} / \mathrm{z}$, in positive polarity and resolution mode. Scan time was set to 0.5 seconds, cone voltage to $30 \mathrm{~V}$, capillary was $3.5 \mathrm{kV}$, trap collision energy was $6 \mathrm{~V}$ and desolvation temperature of $175^{\circ} \mathrm{C}$.

Prior to H/D-X MS experiments, sample preparation and run conditions were optimized by varying concentrations of $\mathrm{GnHCL}(2 \mathrm{M}, 4 \mathrm{M}, 8 \mathrm{M})$, incubation temperature with $\mathrm{D}_{2} \mathrm{O}$ buffer $\left(4^{\circ} \mathrm{C}, 37^{\circ} \mathrm{C}\right)$, flow rate over the pepsin column and HPLC gradient. Conditions listed above yielded the best sequence coverage (greater than 98\%) and resolution in the shortest run time. Furthermore, to minimize rate of back exchange from $\mathrm{D}$ back to $\mathrm{H}$, the sample mixture $\mathrm{pH}$ after the quench reaction was lowered to approximately 2.5 and majority of the run on the instrument was performed at $0{ }^{\circ} \mathrm{C}(48)$. All H/D-X MS experiments were performed under identical conditions, therefore deuterium levels reported are relative and were not corrected for back exchange. Optimized sample preparation and instrument conditions to minimize back exchange from deuterium to hydrogen and triplicate measurements for each sample allowed for high confidence comparability assessments between sample types (49). 


\section{H/D-X MS data analysis}

Mass spectra and chromatography data were acquired using MassLynx (Waters Corp). The peptides were identified and confirmed via $\mathrm{MS}^{2}$ using the PLGS software. The PLGS generated peptide lists and MassLynx acquired mass spectra were imported into the DynamX ${ }^{\mathrm{TM}}$ HDX data analysis software 3.0 (Waters Corp) for further analysis. Only peptides that were identified across all six replicates of each SOD1 variant (example: triplicates of untreated wild-type SOD1 and S-XL6 cross-linked wild-type SOD1) were considered. The maximum sequence length of peptides was set to 45 , minimum peak intensity set to 10,000 , and maximum $\mathrm{MH}+$ error set to $10 \mathrm{ppm}$. Sequence coverage across all samples achieved was $\sim 99 \%$ and the average redundancy for covered amino acids was 11 . The mass spectra were processed within the DynamX software by centroiding the isotopic distribution of various charge states for all the peptides (typically $+2,+3,+4$ ). Deuterium uptake levels were measured by calculating the differences between the centroid of the deuterated peptide vs. the undeuterated reference peptide. These mass shifts and differences are plotted against the exchange timepoints (Fig. S3 for the SOD1 ${ }^{\mathrm{A} 4 \mathrm{~V}}$, SOD1 ${ }^{\mathrm{H} 46 \mathrm{R}}$, SOD1 ${ }^{\mathrm{G} 85 \mathrm{R}}$ $\mathrm{N}$ and $\mathrm{C}$ terminal peptides). Final percentage uptake was calculated by averaging the percent uptake across triplicate measurements utilizing overlapping peptides and recurring residues to elucidate residue level uptake measurements, wherever possible. Three replicates of each sample type were run on different days, and the standard deviation was $\sim 3 \%$ or less. A conservative threshold of $5 \%$ was set during the comparative analysis between sample types and only consistent differences in \% deuterium uptake above $5 \%$ have been emphasized. Peptic maps were obtained from the DynamX software. Maestro 11.8 (Schrödinger Maestro, New York, USA) was used to map the conformational changes onto the crystal structure of wildtype SOD1 (PDB: 1SPD).

\section{Determination of $\mathrm{Cu}$ and $\mathrm{Zn}$ metal content}

All samples were sent to Element Materials Technology (Santa Fe Springs, CA) for quantitation of Cu and Zn metal content via Inductively Coupled Plasma Mass Spectrometry (50). Briefly, a sample portion (0.05 g) was mixed with internal standards (In-Tb-Sc) and then diluted to a final mass of $5 \mathrm{~g}$ with a solution of $0.1 \%$ ammonium hydroxide, $0.05 \%$ EDTA, and $0.05 \%$ Triton $\mathrm{X} 100$. The sample appeared to have completely dissolved. Elements were analyzed on an Agilent 7500 ICP-MS (Agilent Technologies) with an 
octopole collision cell. The standard operating conditions used were RF power: 1550W, Sample depth: 8mm, Carrier gas flow: $1 \mathrm{~L} / \mathrm{min}$, Spray chamber temperature: $2 \stackrel{\circ}{ } \mathrm{C}$, Nebulizer Pump: $0.1 \mathrm{rps}$, Collision gas: $5.4 \mathrm{~mL} / \mathrm{min}$ helium. For quality control, spike recovery experiments were performed where detection limits of $\mathrm{Cu}$ and $\mathrm{Zn}$ were measured to be $0.01 \mathrm{ppm}$ and $1 \mathrm{ppm}$, respectively. Metal content for untreated and SXL6 treated samples are reported in Table S2.

\section{Proteolytic digestion and MALDI-TOF-MS peptide analysis}

Samples of SOD1 ${ }^{\mathrm{A} 4 \mathrm{~V}}$ with or without ten-fold molar excess of $S$-XL6 in $10 \mathrm{mM}$ Tris $\mathrm{HCl}, \mathrm{pH} 7.4$ were incubated for 4 hours at $37^{\circ} \mathrm{C}(51)$. After incubation, samples were alkylated with iodoacetamide (100 mM for 30 minutes), heated to $75{ }^{\circ} \mathrm{C}$ for 20 minutes, and then treated with two volumes of Poroszyme immobilized trypsin (Applied Biosystems, Life Technologies Corporation, Carlsbad, CA, USA) at $37^{\circ} \mathrm{C}$ for 15 minutes, mixing every few minutes to keep beads suspended. Beads were removed by centrifugation before analysis. SOD1 ${ }^{\mathrm{H} 46 \mathrm{R}}$ was incubated with or without ten-fold molar excess of $S$-XL6 and deuterated $S$ XL6 followed by pepsin digestion (1:20 w/w, pepsin:protein) for 120 minutes. Both the digested samples were analyzed using a microflex MALDI-TOF mass spectrometer (Bruker Daltonics, Billerica, Massachusetts, USA) in reflectron mode in the 2-5 kDa range and linear mode in the 4-20 kDa range. Spectra were calibrated using Peptide and Protein I Calibrant (Bruker Daltonics, Billerica, Massachusetts, USA). Matrix only and trypsin digest reaction mixture without SOD1 spectra were acquired as negative controls. Spectra were analyzed in flexAnalysis and BioTools 3.2 (Bruker Daltonics, Billerica, Massachusetts, USA). Peptide mass fingerprinting was performed using MASCOT (Matrix Science, Boston, MA, USA) using trypsin as the enzyme with up to 5 missed cleavages, 100 ppm mass tolerance, and cysteine carbamidomethylation as a variable modification. 
bioRxiv preprint doi: https://doi.org/10.1101/2021.06.23.449516; this version posted June 23, 2021. The copyright holder for this preprint (which was not certified by peer review) is the author/funder. All rights reserved. No reuse allowed without permission.

\section{Acknowledgements}

We thank Dr. George Bou-Assaf for their guidance with the H/D-X MS experiments, Luis Viskatis and Dr. Brian Fahie for their support and encouragement.

\section{Funding}

National Institute of Neurological Disorders and Stroke of National Institute of Health grant R01NS065263 (JNA)

Amyotrophic Lateral Sclerosis (ALS) Association grant 18-IIA-420 (JNA, MJO, RM)

National Science Foundation grant \#MCB-1517290 (MJO)

National Science Foundation grant CHE-1905214 (MJO) 


\section{References}

1. H. Abalkhail, J. Mitchell, J. Habgood, R. Orrell, J. de Belleroche, A new familial amyotrophic lateral sclerosis locus on chromosome 16q12.1-16q12.2. Am J Hum Genet 73, 383-389 (2003).

2. A. Chiò et al., Prognostic factors in ALS: A critical review. Amyotroph. Lateral. Scler. 10, 310-323 (2009).

3. L. Henden et al., Identity by descent analysis identifies founder events and links SOD1 familial and sporadic ALS cases. npj Genomic Medicine 5, 32 (2020).

4. A. E. Renton, A. Chiò, B. J. Traynor, State of play in amyotrophic lateral sclerosis genetics. Nature Neuroscience 17, 17-23 (2014).

5. H. X. Deng et al., Amyotrophic lateral sclerosis and structural defects in $\mathrm{Cu}, \mathrm{Zn}$ superoxide dismutase. Science 261, 1047 (1993).

6. C. Guissart et al., Premature termination codons in SOD1 causing Amyotrophic Lateral Sclerosis are predicted to escape the nonsense-mediated mRNA decay. Scientific Reports 10, 20738 (2020).

7. J. S. Valentine, P. J. Hart, Misfolded CuZnSOD and amyotrophic lateral sclerosis. Proc. Natl. Acad. Sci. U.S.A. 100, 3617-3622 (2003).

8. D. R. Rosen et al., Mutations in $\mathrm{Cu} / \mathrm{Zn}$ superoxide dismutase gene are associated with familial amyotrophic lateral sclerosis. Nature 362, 59-62 (1993).

9. Q. Wang, J. L. Johnson, N. Y. Agar, J. N. Agar, Protein aggregation and protein instability govern familial amyotrophic lateral sclerosis patient survival. PLoS Biol 6, e170 (2008).

10. D. A. Bosco et al., Wild-type and mutant SOD1 share an aberrant conformation and a common pathogenic pathway in ALS. Nat Neurosci 13, 1396-1403 (2010).

11. M. Maier et al., A human-derived antibody targets misfolded SOD1 and ameliorates motor symptoms in mouse models of amyotrophic lateral sclerosis. Science Translational Medicine 10, eaah3924 (2018).

12. Y. Furukawa, E. Tokuda, Does wild-type $\mathrm{Cu} / \mathrm{Zn}$-superoxide dismutase have pathogenic roles in amyotrophic lateral sclerosis? Translational Neurodegeneration 9, 33 (2020).

13. M. E. Gurney et al., Motor neuron degeneration in mice that express a human $\mathrm{Cu}, \mathrm{Zn}$ superoxide dismutase mutation. Science 264, 1772-1775 (1994).

14. G. S. Wright, S. V. Antonyuk, N. M. Kershaw, R. W. Strange, S. Samar Hasnain, Ligand binding and aggregation of pathogenic SOD1. Nat Commun 4, 1758 (2013).

15. R. J. Nowak, G. D. Cuny, S. Choi, P. T. Lansbury, S. S. Ray, Improving binding specificity of pharmacological chaperones that target mutant superoxide dismutase-1 linked to familial amyotrophic lateral sclerosis using computational methods. J Med Chem 53, 2709-2718 (2010).

16. M. S. Maurer et al., Tafamidis Treatment for Patients with Transthyretin Amyloid Cardiomyopathy. New England Journal of Medicine 379, 1007-1016 (2018).

17. S. S. Ray, R. J. Nowak, R. H. Brown, Jr., P. T. Lansbury, Jr., Small-molecule-mediated stabilization of familial amyotrophic lateral sclerosis-linked superoxide dismutase mutants against unfolding and aggregation. Proc. Natl. Acad. Sci. U.S.A. 102, 3639-3644 (2005).

18. V. Koppaka et al., Aldehyde dehydrogenase inhibitors: a comprehensive review of the pharmacology, mechanism of action, substrate specificity, and clinical application. Pharmacol Rev 64, 520-539 (2012).

19. L. Olbe, E. Carlsson, P. Lindberg, A proton-pump inhibitor expedition: the case histories of omeprazole and esomeprazole. Nat Rev Drug Discov 2, 132-139 (2003).

20. D. Li et al., BIBW2992, an irreversible EGFR/HER2 inhibitor highly effective in preclinical lung cancer models. Oncogene 27, 4702-4711 (2008).

21. J. R. Auclair, K. J. Boggio, G. A. Petsko, D. Ringe, J. N. Agar, Strategies for stabilizing superoxide dismutase (SOD1), the protein destabilized in the most common form of familial amyotrophic lateral sclerosis. Proc. Natl. Acad. Sci. U.S.A. 107, 21394-21399 (2010).

22. D. A. Cooney, H. A. Milman, R. G. Cable, R. L. Dion, V. H. Bono, Jr., Maleimide--biochemical, pharmacologic and toxicologic studies. Interaction with L-asparagine metabolism. Biochem Pharmacol 27, 151-166 (1978).

23. M. J. Capper et al., The cysteine-reactive small molecule ebselen facilitates effective SOD1 maturation. Nature Communications 9, 1693 (2018).

24. V. Chantadul et al., Ebselen as template for stabilization of A4V mutant dimer for motor neuron disease therapy. Communications Biology 3, 97 (2020). 
25. D. P. Donnelly et al., Cyclic Thiosulfinates and Cyclic Disulfides Selectively Cross-Link Thiols While Avoiding Modification of Lone Thiols. Journal of the American Chemical Society 140, 7377-7380 (2018).

26. P. B. Stathopulos et al., Cu/Zn superoxide dismutase mutants associated with amyotrophic lateral sclerosis show enhanced formation of aggregates in vitro. Proc. Natl. Acad. Sci. U.S.A. 100, 70217026 (2003).

27. F. H. Niesen, H. Berglund, M. Vedadi, The use of differential scanning fluorimetry to detect ligand interactions that promote protein stability. Nature Protocols 2, 2212-2221 (2007).

28. K. Amporndanai et al., Novel Selenium-based compounds with therapeutic potential for SOD1linked amyotrophic lateral sclerosis. EBioMedicine 59 (2020).

29. Y.-T. Liu et al., Biophysical characterization and modulation of Transthyretin Ala97Ser. Annals of Clinical and Translational Neurology 6, 1961-1970 (2019).

30. F. Nakashima et al., Structural and functional insights into S-thiolation of human serum albumins. Scientific Reports 8, 932 (2018).

31. K. C. Aluri et al., Cyclic Thiosulfinates as a Novel Class of Disulfide Cleavable Cross-Linkers for Rapid Hydrogel Synthesis. Bioconjugate Chemistry 32, 584-594 (2021).

32. J. M. McCord, I. Fridovich, Superoxide dismutase. An enzymic function for erythrocuprein (hemocuprein). J Biol Chem 244, 6049-6055 (1969).

33. A. J. Pratt et al., Aggregation propensities of superoxide dismutase G93 hotspot mutants mirror ALS clinical phenotypes. Proc. Natl. Acad. Sci. U.S.A. 111, E4568 (2014).

34. G. S. A. Wright, S. V. Antonyuk, N. M. Kershaw, R. W. Strange, S. Samar Hasnain, Ligand binding and aggregation of pathogenic SOD1. Nature Communications 4, 1758 (2013).

35. T. E. Wales, J. R. Engen, Hydrogen exchange mass spectrometry for the analysis of protein dynamics. Mass Spectrom Rev 25, 158-170 (2006).

36. J. S. Elam et al., Amyloid-like filaments and water-filled nanotubes formed by SOD1 mutant proteins linked to familial ALS. Nat Struct Biol 10, 461-467 (2003).

37. L. McAlary, J. A. Aquilina, J. J. Yerbury, Susceptibility of Mutant SOD1 to Form a Destabilized Monomer Predicts Cellular Aggregation and Toxicity but Not In vitro Aggregation Propensity. Front Neurosci 10, 499 (2016).

38. P. Ip, V. K. Mulligan, A. Chakrabartty, ALS-causing SOD1 mutations promote production of copperdeficient misfolded species. J Mol Biol 409, 839-852 (2011).

39. L. J. Hayward et al., Decreased metallation and activity in subsets of mutant superoxide dismutases associated with familial amyotrophic lateral sclerosis. J Biol Chem 277, 15923-15931 (2002).

40. T. Kabuta, Y. Suzuki, K. Wada, Degradation of Amyotrophic Lateral Sclerosis-linked Mutant Cu,ZnSuperoxide Dismutase Proteins by Macroautophagy and the Proteasome. Journal of Biological Chemistry 281, 30524-30533 (2006).

41. B. F. Shaw et al., Detergent-insoluble aggregates associated with amyotrophic lateral sclerosis in transgenic mice contain primarily full-length, unmodified superoxide dismutase-1. J Biol Chem 283, 8340-8350 (2008).

42. J. R. Williams et al., Copper delivery to the CNS by CuATSM effectively treats motor neuron disease in SOD(G93A) mice co-expressing the Copper-Chaperone-for-SOD. Neurobiol Dis 89, 19 (2016).

43. D. P. Donnelly et al., Best practices and benchmarks for intact protein analysis for top-down mass spectrometry. Nature Methods 16, 587-594 (2019).

44. M. R. Packer et al., Raf promotes dimerization of the Ras G-domain with increased allosteric connections. Proc. Natl. Acad. Sci. U.S.A. 118, e2015648118 (2021).

45. A. Nozari et al., Prolonged therapy with the anticonvulsant carbamazepine leads to increased plasma clearance of fentanyl. J Pharm Pharmacol 71, 982-987 (2019).

46. K. Manalastas-Cantos et al., ATSAS 3.0: expanded functionality and new tools for small-angle scattering data analysis. J. Appl. Crystallogr. 54, 343-355 (2021).

47. E. F. Pettersen et al., UCSF Chimera--a visualization system for exploratory research and analysis. J. Comput. Chem. 25, 1605-1612 (2004).

48. J. R. Engen, T. Botzanowski, D. Peterle, F. Georgescauld, T. E. Wales, Developments in Hydrogen/Deuterium Exchange Mass Spectrometry. Analytical Chemistry 10.1021/acs.analchem.0c04281 (2020). 
bioRxiv preprint doi: https://doi.org/10.1101/2021.06.23.449516; this version posted June 23, 2021. The copyright holder for this preprint (which was not certified by peer review) is the author/funder. All rights reserved. No reuse allowed without permission.

49. G. R. Masson et al., Recommendations for performing, interpreting and reporting hydrogen deuterium exchange mass spectrometry (HDX-MS) experiments. Nature Methods 16, 595-602 (2019).

50. J. P. Mondia et al., Using X-ray fluorescence to measure inorganics in biopharmaceutical raw materials. Analytical Methods 7, 3545-3550 (2015).

51. Y. A. Wang et al., Integrated Bottom-Up and Top-Down Liquid Chromatography-Mass Spectrometry for Characterization of Recombinant Human Growth Hormone Degradation Products. Analytical Chemistry 89, 12771-12777 (2017). 
bioRxiv preprint doi: https://doi.org/10.1101/2021.06.23.449516; this version posted June 23, 2021. The copyright holder for this preprint (which was not certified by peer review) is the author/funder. All rights reserved. No reuse allowed without permission. 